\title{
Towards a calibration laboratory in $\mathrm{Ny}$-Ålesund
}

\author{
Chiara Musacchio $^{1}$ - Andrea Merlone ${ }^{1} \cdot$ Angelo Viola $^{2}$ - Vito Vitale ${ }^{2}$. \\ Marion Maturilli ${ }^{3}$
}

Received: 30 November 2015/ Accepted: 20 April 2016

(C) Accademia Nazionale dei Lincei 2016

\begin{abstract}
Multitudes of measurements are needed to understand the environment and its evolution. The Arctic region is a fundamental observation area for climate change evaluation: climate change comes first and comes faster in the arctic. The higher accuracy required to quickly capture trends; the extreme range and conditions of sensors exposure; a robust comparability asked by the different measurement networks; the need of dedicated calibration procedures, together with the logistical problems associated with such remote location, motivate the proposal for a joint effort to address metrology experience and activities for Arctic research applications. The Ny-Ålesund international research base and community offers a unique infrastructure to directly link metrological traceability to on site polar measurements. The contribution reports a study on the implementation of specific calibration procedures, metrological validation of measurements and instrument tests, uncertainties evaluations including quantities of influence, and the feasibility of a metrology laboratory in Ny-Ålesund.
\end{abstract}

This peer-reviewed article is a result of the multi and interdisciplinary research activities based at the Arctic Station "Dirigibile Italia", coordinated by the "Dipartimento Scienze del Sistema Terra e Tecnologie per l'Ambiente" of the National Research Council of Italy.

Chiara Musacchio

a.merlone@inrim.it

1 Thermodynamics Division, Istituto Nazionale di Ricerca Metrologica (INRiM), Turin, Italy

2 Istituto di Scienze dell'Atmosfera e del Clima Consiglio Nazionale delle Ricerche, Bologna, Italy

3 Helmholtz Center for Polar and Marine Research, Alfred Wegener Institute (AWI), Potsdam, Germany
Keywords Metrology · Ny-Ålesund · MeteoMet · Arctic . Climate $\cdot$ Calibration $\cdot$ Calibration laboratory

\section{Introduction}

In recent years, a growing interaction between the metrology community and the meteorology and climatology communities, including researchers working on atmospheric, oceanic and terrestrial observations, has been established through effective collaborations. The signature of the Mutual Recognition Arrangement (MRA) between the World Meteorological Organization (WMO), the International Office of Weights and Measures (Bureau international des poids et mesures-BIPM), creation of Task Groups addressing environmental metrology by BIPM and the European Association of National Institutes of Metrology (EURAMET), the launch of joint research projects on metrology for environment, the mutual exchange of memberships between the two communities [metrologists now sit in WMO commissions, in the Global Climate Observing System (GCOS)—Reference Upper Air Network (GRUAN) and other international institutions while climatologists and researchers on climate observations are members of BIPM and EURAMET task groups], all are the consequences of this evolving liaisons.

Arctic observation of atmospheric, terrestrial and marine variables and phenomena are well known to be fundamental to understand climate evolutions due to the amplified effects involving such unique environment (Maturilli et al. 2013, and references therein). At Ny-Ålesund-Svalbard a $34 \mathrm{~m}$ high tower, the Italian Climate Change Tower (CCT) is also installed to provide continuous time series of atmospheric parameters at different height that are very important to study the processes occurring in the atmospheric boundary 
layer. Accurate measurements are needed to quickly capture trends and with higher reliability. Metrological traceability is moreover fundamental to establish robust comparability among the multitude of observations made in different locations, over time and by different research groups. In this context also the measurements of temperature and humidity profiles, obtained by fast and slow response sensors at the CCT [Mazzola et al. 2016; Tampieri et al. 2016, (this issue)] must be subject to inter-comparability based on the accuracy and calibration traceability with other measurements gathered by different sensors in different sites.

The needs of data quality and comparability, uncertainty evaluation, measurements accuracy and dedicated calibrations of instruments are now clearly identified. In this contest, addressing such emerging metrology needs was funded and is now operative the EURAMET project "MeteoMet-Metrology for Meteorology" that groups a wide consortium of 20 European National Institutes of Metrology, Universities, Research Centres, Hydro-Meteo Agencies and Manufacturers (Merlone et al. 2013, 2015).

\section{The "2014 Arctic Metrology calibration campaign"}

In 2014, as a task included among the MeteoMet objectives, the "Arctic Metrology" campaign was concluded. A special calibration chamber (Lopardo et al.), equipped with pressure and temperature sensors, traceable to primary standards of the International System of Units (SI), was manufactured by the Italian Institute of Metrology and shipped to Ny-Ålesund.

Three metrologists then reached Ny-Ålesund and assembled the system, which was used to calibrate the sensors involved in the pre-launch ground check of radiosondes, for the GRUAN station operated by the German Alfred Wegener Institute (AWI). As radiosondes perform balloon-borne in situ measurements of atmospheric vertical profiles, the quantification of their measurement uncertainty is a key issue when it comes to the detection of climate change signals. Therefore within GRUAN, the independent ground-check of the radiosonde sensors with calibrated instrumentation is crucial. While the chamber was available on site, it was also used to calibrate some sensors operated at the Italian Climate Change Tower (CCT) of CNR.
This work showed the advantages of having calibration system available on site, and the unique value arising from establishing a well documented traceability chain from the measurement, to the primary SI standards. After the calibration of a first set of thermometers, which results have already been published (Musacchio et al. 2015), the availability of the system on site and the fact that all the equipment was in complete working condition, suggested to use the remaining few days at the base to calibrate a further set of sensors. The results of this calibration have still not been published and are here reported.

The uncertainty budget was composed of the main components reported in Table 1, where the maximum measured value is reported, to represent the "worst" case as maximum uncertainty value. The components are generated by the uncertainty in the calibration of the reference standard, the characteristic of the chamber, in terms of temperature uniformity and stability and, the electrical and thermal noise of the sensor under calibration, considered together as a single uncertainty on the sensors response.

The calibration was made reading the values originated by the sensors under calibration and comparing them with those recorded by a reference standard, when the temperature in the chamber was detected to be stable at the required level, decided to be within a couple of millikelvin for the duration of the recording at each point. The calibration points were defined together with the local operating scientist, according to the sensors exposure when positioned in field. Those were $-30,-25,-15,0$ and $10{ }^{\circ} \mathrm{C}$, with a return to $0{ }^{\circ} \mathrm{C}$ to evaluate potential hysteresis, not detected. Table 2 reports an example of acquisition at $25^{\circ} \mathrm{C}$ for three thermometers.

The differences of the readings of the sensors under calibration and the temperature values recorded by the reference standards were calculated from the mean of almost ten reading, in stable temperature conditions, for each point and each thermometer. A curve best fitting those differences in function of the temperature point was then calculated: this is the calibration curve and it can be embedded in the data logging system or as post-processing correction. The residuals were then evaluated for the calibration points and included as Type A uncertainty. Fig. 1 reports the residual curve (Type A uncertainty) and the associated instrumental (Type B) uncertainty.

The overall extended uncertainty (coverage factor $k=2$ ) for each sensor was then evaluated to be:
Table 1 Measured instrumental uncertainty components (Type B uncertainty)

\begin{tabular}{ll}
\hline Uncertainty budget contribution & Value/K \\
\hline Temperature reference sensor & 0.011 \\
Chamber uniformity & 0.019 \\
Chamber stability (during the calibration comparison duration time required) & 0.001 \\
Sensor under calibration & 0.0 .014 \\
\hline
\end{tabular}


Table 2 Example of data recorded during the contemporary calibration of three temperature sensors (PRT01-02-03) against the reference thermometer (temp ref)

\begin{tabular}{|c|c|c|c|c|c|}
\hline \multicolumn{6}{|c|}{ Calibration ID: Ny-Ålesund AWI_GRUAN_Arctic Metrology 2014—Tab 03} \\
\hline \multicolumn{3}{|c|}{ Date: 20140723} & \multicolumn{3}{|c|}{ Time: $9.32 \mathrm{AM}$} \\
\hline \multicolumn{3}{|c|}{ Nominal temperature point $-25^{\circ} \mathrm{C}$} & \multicolumn{3}{|c|}{ Sampling interval $10 \mathrm{~s}$} \\
\hline no & Temp ref $/{ }^{\circ} \mathrm{C}$ & PRT $01 /{ }^{\circ} \mathrm{C}$ & PRT $02 /{ }^{\circ} \mathrm{C}$ & $\operatorname{PRT} 03 /{ }^{\circ} \mathrm{C}$ & Note (if any) \\
\hline 1 & -23.933 & -23.84 & -23.80 & -23.98 & \\
\hline 2 & -23.932 & -23.83 & -23.80 & -23.98 & \\
\hline 3 & -23.931 & -23.84 & -23.80 & -23.98 & \\
\hline 4 & -23.931 & -23.83 & -23.80 & -23.98 & \\
\hline 5 & -23.931 & -23.83 & -23.80 & -23.98 & \\
\hline 6 & -23.931 & -23.84 & -23.80 & -23.97 & \\
\hline 7 & -23.931 & -23.83 & -23.80 & -23.99 & \\
\hline 8 & -23.930 & -23.84 & -23.80 & -23.99 & \\
\hline 9 & -23.930 & -23.83 & -23.80 & -23.97 & \\
\hline 10 & -23.931 & -23.83 & -23.81 & -23.98 & \\
\hline Mean & -23.931 & -23.833 & -23.799 & -23.977 & \\
\hline St.dev & 0.001 & 0.004 & 0.003 & 0.006 & \\
\hline
\end{tabular}

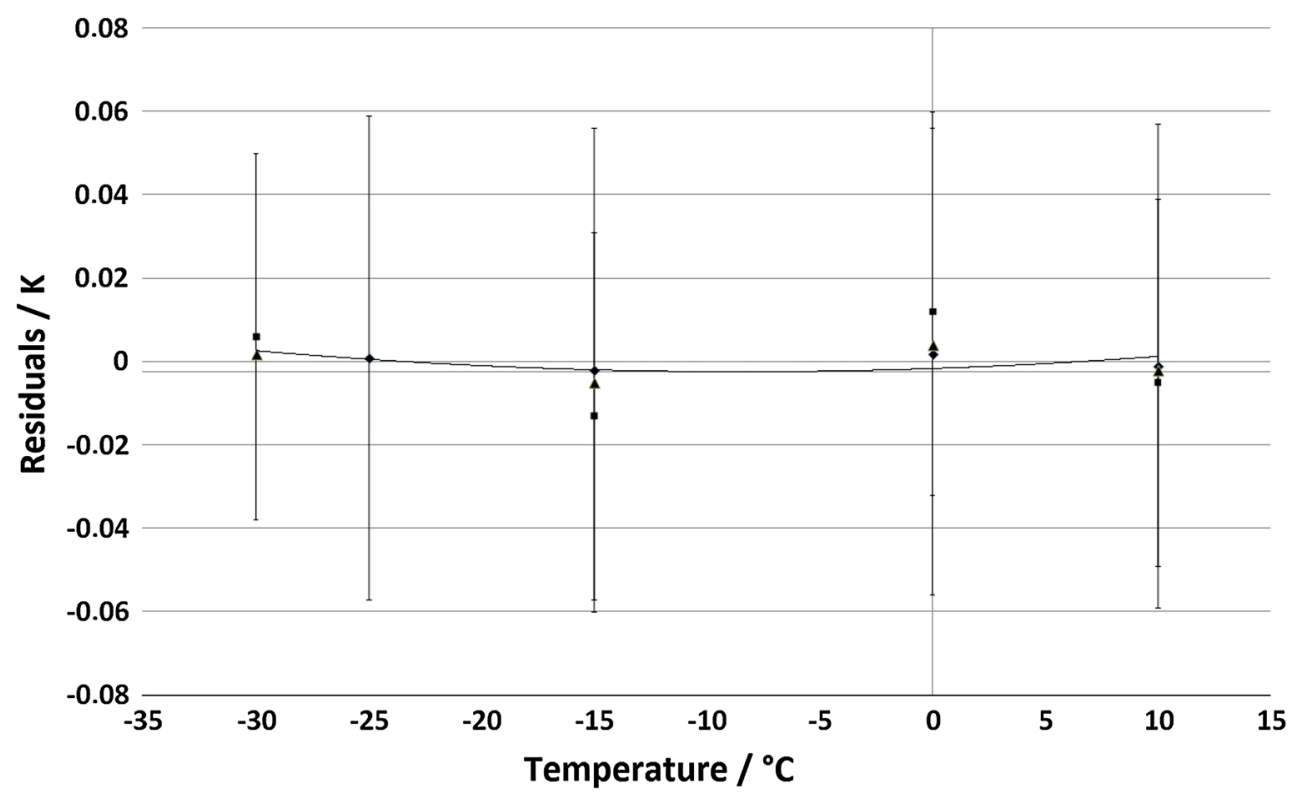

Fig. 1 Calibration function residuals and associated uncertainty: PRT01 diamond dots, PRT02 square dots, PRT03 triangular dots

$u_{\mathrm{PRT} 01}=0.027 \mathrm{~K}$
$u_{\mathrm{PRT} 02}=0.046 \mathrm{~K}$
$u_{\mathrm{PRT} 03}=0.033 \mathrm{~K}$

\section{Follow-up process}

The collaboration of the researcher operating the Arctic base and the metrologists was fruitful in terms of discussing and defining dedicated calibration procedure, according to instrument use and target uncertainties.
Following this positive experience, a workshop was organised to discuss ideas and proposals for implementing metrology in the Arctic. The first "Arctic Metrology workshop" was held in Torino on 23 April 2015, focussed:

- to address metrology experience and activities in support of the arctic research,

- to present the expertise of metrology institutes and universities, for the science in the Arctic,

- to plan a joint effort towards the creation of a permanent metrology structure for arctic research. 
Participants at the workshop came from NMIs, Research Institutes operating in Ny-Ålesund, Universities; a representative of CIMO-WMO was also present.

The main outcomes of the workshop presentations and of the round table closing discussion have been:

(A) the definition of the specific need motivating the presence of a calibration laboratory in $\mathrm{Ny}$-Ålesund;

(B) the proposal of further activities addressing metrology in support of arctic research, such as evaluation of field measurements uncertainty, including the effect of influence quantities;

(C) the identification of the expertise available from the participating NMIs;

(D) the planning of further actions for promoting, preparing and submitting a project proposal for the activities related to implementing metrology for the $\operatorname{arctic}$ (point $\mathrm{A}$ and $\mathrm{B}$ )

About point $\mathrm{A}$, the following needs were identified.

\subsection{Measurements accuracy and comparability}

In general, for any kind of research, based on measured data, accuracy is necessary

to reduce the time necessary to capture a trend,

to better understand the observed phenomena,

to improve the quality of input data for models.

Measurement accuracy is obtainable primarily through a well-documented metrological traceability to SI standards. Data traceability establishes comparability in the records which is of fundamental importance in the multitude of measurements performed in the Svalbard. Result comparability is required

across instrument and measurement types and locations, across different organizations and different nations, across generations of researchers, on climate-change scales, to fundamental physical models.

\subsection{Arctic metrology workshop conclusions and outcomes}

The workshop participants concluded that the availability of a metrology and calibration infrastructure in Svalbard would benefit the research and observational studies for the following reasons:

- The definition of specific calibration procedures, and associated uncertainty evaluation, not available by usual calibration services and accredited laboratories, to take into account the extreme ranges of variability of the key-quantities measured the exposure of the sensors to challenging conditions and more relevant effects of the quantities of influence.

- Surpassing the logistical difficulties in reaching, removing, handling instruments for the calibration campaigns requires self validating in situ measurements and calibration devices operating in Arctic-based research stations.

- An active role played by arctic researchers and operators in defining common calibration procedures in cooperation with metrologists.

- The opportunity for researchers to directly follow and take part in the calibration and test of their instruments.

- The adoption of unique calibration procedures, to avoid different national approaches and unnecessary discrepancies, incrementing the comparability of the instruments response.

- Time and funds saved in shipping instruments to national calibration services.

- A central infrastructure to benefit all researchers operating in the area, with an agreed common implementation plan.

- Direct traceability to primary standards of the System of Units, arising from the involvement of National Institutes of Metrology, to reduce calibration uncertainty.

Those conclusions were then presented at the Arctic Circle Assembly, in Reykjavik, 16-19 October 2016, where a breakout session on "Metrology for Environment in the Arctic" was organised by EURAMET in cooperation with the Italian Embassy in Oslo and with the endorsement and support of BIPM. There, researchers operating in the Arctic, WMO Research Instrument Center representative and metrologists refined the proposal of the project aimed at implementing metrology in the Svalbard.

The Arctic environment is fundamental for Europe. Europe has a number of countries having borders, coasts or even land within the Arctic Circle and being member of the Arctic Council. Environmental monitoring in the Arctic is therefore of utmost importance for those EU countries since it influences infrastructure developing, shipping, fishing, adaptation (animal, vegetal, human), oil and gas. This motivates presenting a project for funding also in the framework of the European Metrology Programme for Innovation and Research

A further reason, on the scientific side, is that in $\mathrm{Ny}$ Alesund many EU countries are carrying on research activities in this polar station and research area. A common and unique approach among such research groups in establishing data comparability and measurement procedure is of relevant impact for the data quality itself and the value of the achieved results in many investigated areas. 
NMI involvement is needed since usual calibration accredited laboratories or manufacturers are not in charge to assist research teams in:

1. developing dedicated calibration procedures including mutual analysis of quantities,

2. influencing quantity evaluation, correction or inclusion in uncertainty,

3. study of field measurement uncertainty (not approachable by providers and sometimes a hard task for nonexperts in metrology researchers).

Moreover, direct and shorter chain to higher quality standards improves the overall uncertainty. As an example, the need of $0.1{ }^{\circ} \mathrm{C}$ uncertainty in temperature measurements seems "easy" to achieve, but when all the aspects of the calibration and measurement are evaluated and included, starting from a calibration at millikelvin level becomes crucial, to avoid uncertainty degrades quickly well surpassing the target idea, as shown in the following scheme of Fig. 2.

Multidisciplinary approach can only be provided by metrology networks of which NMIs are in a central position, linking multitudes of laboratories, instrument providers and research institutions. EURAMET role and mission is, among the other, also enforcing such capillary liaisons. Maximum impact can be achieved if the research agendas are used to target long-term objectives, to enable and

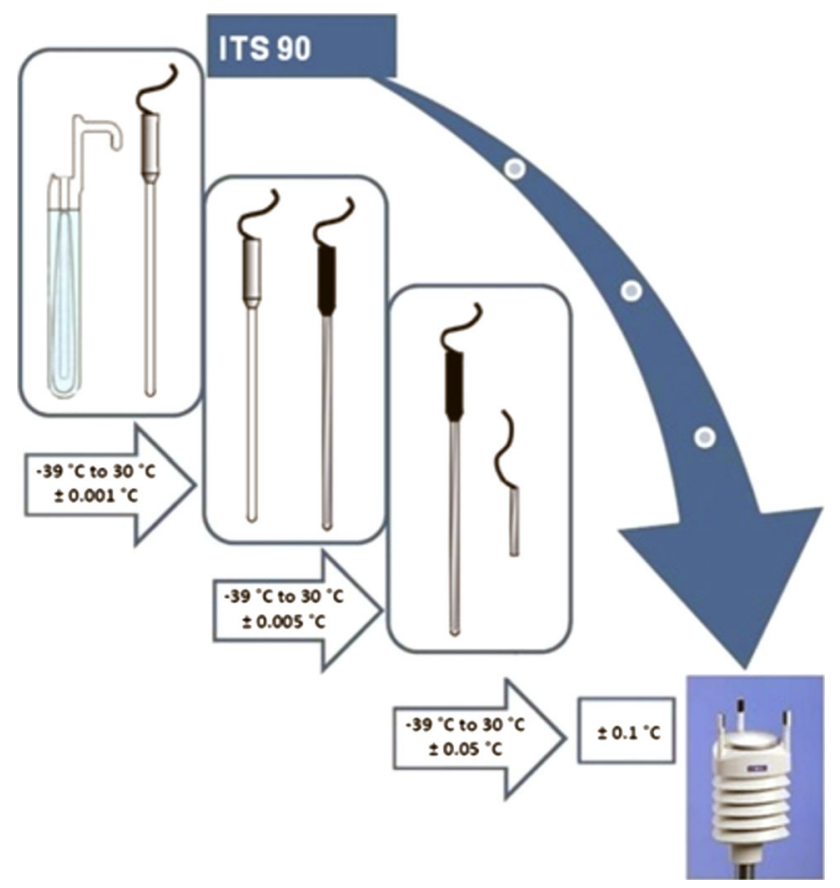

Fig. 2 An example scheme of calibration traceability for temperature instruments: from the SI standards, the ITS-90 fixed points, to an automatic weather station. How the uncertainty degrades well before even evaluating measurement uncertainty stimulate related investments in facilities and equipment, and pooling of metrological resources across national boundaries to tackle key societal challenges. (EURAMET strategic document, issued 15-9-2011).

The support from the metrology community to the Arctic research has been structured in two main tasks: measurement uncertainty evaluation and implementation of a calibration laboratory.

\section{Measurement uncertainty evaluation}

Measurements are affected by uncertainties, representing the dispersion of the values that could be reasonably attributed to the measurand (GUM 2008). The evaluation of the uncertainty is normally based on the identification of a number of components and their weight on the total uncertainty budget. Declaring a measurement result without expressing the associated uncertainty is physically not correct and makes the measurement process lose its significance. On the contrary, a well documented uncertainty guarantees the reliability of the measured value and a deeper knowledge of the observation.

Field measurements are usually affected by a large number of uncertainty components such as: instrument stability, site characteristics, quantities of influence (like temperature, radiation, wind and their mutual influences, etc.), calibration, handling, data logging, recording frequency, and many others. Even the measurand itself is not always known without a reasonable uncertainty, like in air temperature value. In extreme conditions, such as those encountered by the instrument positioned in Arctic environment, further contribution to the overall uncertainty arises from the environmental characteristics and the sensor exposure to extreme conditions. Polar night and polar day, and unusual sun position (i.e. effecting radiometers), strong winds, long lasting cold temperatures, ice and melts, shocks, cold temperature vs high radiative effects all of them affect the stability of sensors. Calibrations are required to be more frequent to keep the sensors under appropriate and known working conditions. Logistical difficulties, moreover, make it an advantage to have a lab on site to provide instrument checks and calibrations.

\section{Implementation of a calibration laboratory}

A possible process towards the creation of a metrology laboratory in Ny-Ålesund.

Based on the experience achieved during the "Arctic Metrology" campaign of 2014, the benefit of having calibration facilities, devices and infrastructures, 
available on site was clearly demonstrated (Musacchio et al. 2015).

A plan to implement a calibration laboratory in one of the structures available in Ny-Ålesund was then started. The first step was to focus on a roadmap and a sequence of actions including a list of priorities in terms of quantities and variables of interest, a work to identify possible funding sources, the technical aspects of the first systems to be delivered.

About the quantities to be preliminary considered for making calibration devices available in Ny-Ålesund, the discussions between metrologists and scientists operating in the Arctic, during the several workshops and conferences in 2014 and 2015, highlighted the already existing availability and possible immediate progresses in this direction. Metrologists from key European NMI studied the possibility to start the creation of specific devices in spring 2016. A project is then being defined, also in terms of its presentation as proposal for funding, and in synthesis it identifies the following:

- acquisition of a commercial climatic chamber and definition of a dedicated set of instruments to adapt such chamber to more specific use and calibration procedures, for air temperature and humidity sensors;

- construction of a special climatic chamber to allow temperature and pressure sensors calibration, including the possibility to evaluate the mutual influences on sensors from both quantities similar to what already used in 2014 [Meteorological Applications, 2015, Arctic metrology: Calibration of radiosondes ground check sensors in Ny-Ålesund];

- construction of a specific liquid bath for the calibration of sensors used to measure temperature in sea water, lakes, ice and permafrost (Zandt et al. 2011);

- survey of target uncertainty in temperature measurements in identified field measurements;

- definition of availability of metrology staff and training of dedicated staff for the first years of implementation of the calibration laboratory;

- identification of logistical requirements and available room in Ny-Ålesund to host the calibration laboratory.

This project proposal can be an added value also to the Svalbard Integrated Earth Observing System (SIOShttp://www.sios-svalbard.org/prognett-sios/Home_page/

1234130481072). SIOS is an international infrastructure project involving partners from Europe and Asia with the objective to coordinate and develop existing and new research infrastructures in Svalbard. The proposal of permanent metrology common laboratories can perfectly fit the SIOS mission.

\subsection{Key dates}

June 2014 “Arctic Metrology Campaign”. Metrologists from the MeteoMet project reached Ny-Ålesund, having preliminary shipped a special calibration chamber and auxiliary equipment. The campaign involved the calibration of the instruments used by the AWIPEV research base for the pre-launch ground check of radiosondes temperature and pressure sensors. Thermometers installed in the Italian Climate Change Tower were calibrated too.

September 2014 The first "Metrology for Meteorology and Climate" conference, with about 150 participants form four continents, organized by the MeteoMet project in Brdo, Slovenia, includes a session on Arctic activities, where the results of the $\mathrm{Ny}$-Ålesund campaign are presented.

23 April 2015 As a MeteoMet meeting, the first "Arctic Metrology" workshop is organized in Torino, Italy. Staff from Institute of metrology and researchers operating in Arctic Stations gathered together to discuss common plans.

21 September 2015 Italian researchers operating in NyAlesund and the MeteoMet Coordinator meet with the Italian Ambassador in Norway, to plan the participation at the "Arctic Circle assembly" and receiving full diplomatic support for implementing metrology in the Svalbard.

22-25 September 2015 At the Ny-Ålesund seminar, the preliminary idea about the creation of a calibration laboratory in Ny-Ålesund is presented and discussed. Again Metrologists and researcher in Arctic stations met.

16-18 October 2015 EURAMET promotes a breakout session at the Arctic Circle Assembly with the title "Metrology for Environment in the Arctic". The international event, this year opened by French President François Hollande, was attended by 1900 participants, with a high diplomatic and scientific content and outcome. The EURAMET session was supported by BIPM (Bureau International des Poids et Measures).

1st December 2015 The European Metrology Programme for Innovation and Research of EURAMET and the Task Group on Metrology for Environment organize the Workshop "Presentation of ideas in preparation for the: Targeted Programme Environment in 2016" on 1st December 2015. A breakout session on "Metrology for Extreme Environment" is included and will address the needs and objectives of a funding proposal that includes metrology for Arctic research.

May 2016 In Oslo the second workshop on "Arctic Metrology" is planned

26-30 September 2016 The "MMC 2016" second conference on "Metrology for Meteorology and Climate" will be held in Madrid, Spain, together with the WMO CIMO TECO conference and the Meteorological 
Exhibition. A session on data quality for Arctic research is planned.

\section{Conclusions}

As the Arctic region is a fundamental observation point for climate change (IPCC 2007) and considering examples of integrated project as the CCT, relevance of this proposal is also to underline the opportunity to perform calibration and traceability on site, to give direct metrological robustness to measurement related to environmental and climate studies to improve comparability and representativeness of datasets.

During the last couple of years, numerous events opened the road to fruitful discussion between the metrologists and research staff operating in the arctic area, aiming at planning the feasibility for the establishment of a permanent laboratory for metrology in $\mathrm{Ny}$-Ålesund to support on site the research stations in Svalbard. The proposal will initially deal with temperature (of air, water, ice, soil, and permafrost), pressure, humidity (air humidity and soil moisture), radiance (direct solar radiation, albedo, etc.), and salinity. The availability of a metrology laboratory on site can definitely facilitate for research communities dealing with calibration and instrument performance tests, avoiding at the same time transfer of instrumentation to calibration services in the mainland. Having a metrology laboratory on site, moreover, will surely extend awareness on metrological needs and benefit in this field.

The proposed onsite metrological laboratory equipped with specific devices can establish long-term direct traceability of the measurements in polar area, with a direct link to primary standards of European National Metrology Institutes. A preliminary campaign performed in 2014, involving a transportable calibration chamber, showed the advantage of having a calibration facility operating in $\mathrm{Ny}$ Allesund: several thermometers and a couple of barometers were calibrated. The barometers were also calibrated at different temperatures, to check and correct eventual temperature drift, especially at the lower temperature occurring in polar environment. Both temperature and pressure calibration were made by comparison against reference standards. The reference standard for temperature was previously calibrated at INRiM against a primary Standard Platinum Reference Thermometer calibrated at the ITS-90 fixed points primary standards as maintained at INRiM. This process fully documents the measurement traceability to primary SI standards and allows the same staff from the NMI to completely evaluate the whole uncertainty, from a national standard, out to the field records. This is part of the added value of this proposal. This will benefit the quality of data available in the immediate short period as well as for the future generation of climatologists.

Acknowledgments This work is being developed within the frame of the European Metrology Research Program (EMRP) joint research project ENV58 "METEOMET2". The EMRP is jointly funded by the EMRP participating countries within EURAMET and the European Union.

\section{References}

GUM (2008): BIPM, IEC, IFCC, ILAC, ISO, IUPAC, IUPAP, and OIML. Evaluation of measurement data-guide to the expression of uncertainty in measurement. Joint Committee for Guides in Metrology, JCGM 100:2008

IPCC (2007) Climate Change 2007: Synthesis Report. In: Pachauri RK, Reisinger A (eds) Contribution of Working Groups I, II and III to the Fourth Assessment, Report of the Intergovernmental Panel on Climate Change [Core Writing Team]. IPCC, Geneva, Switzerland, pp 104

Maturilli M, Herber A, König-Langlo G (2013) Climatology and time series of surface meteorology in Ny-Ålesund, Svalbard. Earth Syst Sci Data 5:155-163. doi:10.5194/essd-5-155-2013

Mazzola M, Viola AP, Lanconelli C, Vitale V (2016) Atmospheric observations at the Amundsen-Nobile Climate Change Tower in Ny-Ålesund, Svalbard. Rend Fis Acc Lincei (submitted)

Merlone A, Lopardo G, Antonsen I, Bell S, Benyon R, Boese N, del Campo D, Dobre M, Drnovšek J, Elkatmis A, Georgin E, Grudniewicz E, Heinonen M, Holstein-Rathlou C, Johansson J, Klason P, Knorova R, Melvad C, Merrison J, Migała K, de Podesta M, Saathoff H, Smorgon D, Sparasci F, Strnad R, Szmyrka-Grzebyk A, Vuillermoz E (2013) A new challenge for meteorological measurements: the MeteoMet project-metrology for meteorology. AIP Conf Proc 1552:1030-1035

Merlone A, Lopardo G, Sanna F, Bell S, Benyon R, Bergerud RA, Bertiglia F, Bojkovski J, Böse N, Brunet M, Cappella A, Coppa G, del Campo D, Dobre M, Drnovsek J, Ebert V, Emardson R, Fernicola V, Flakiewicz K, Gardiner T, Garcia-Izquierdo C, Georgin E, Gilabert A, Grykalowska A, Grudniewicz E, Heinonen M, Holmsten M, Hudoklin D, Johansson J, Kajastie H, Kaykisizli H, Klason P, Kňazovická L, Lakka A, Kowal A, Müller H, Musacchio C, Nwaboh J, Pavlasek P, Piccato A, Pitre L, de Podesta M, Rasmussen MK, Sairanen H, Smorgon D, Sparasci F, Strnad R, Szmyrka-Grzebyk A, Underwood R (2015) The MeteoMet project-metrology for meteorology: challenges and results. Meterol Appl 22:820-829. doi:10.1002/met.1528

Musacchio C, Bellagarda S, Maturilli M, Graeser J, Vitale V, Merlone A (2015) Arctic metrology: calibration of radiosondes ground check sensors in Ny-Ålesund. Meterol Appl 22:854-860. doi:10. 1002/met.1506

Tampieri F, Viola AP, Mazzola M, Pelliccioni A (2016) On turbulence characteristics at Ny-Ålesund-Svalbard. Rend Fis Acc Lincei. doi:10.1007/s12210-016-0526-6 (this issue)

Zandt T, Fellmuth B, Gaiser C, Kuhn A, Merlone A, Moro F, ThieleKrivoi B (2011) Capabilities for dielectric-constant gas thermometry in a special large-volume liquid-bath thermostat. Int $\mathbf{J}$ Thermophys 32(7-8):1355-1365 